\title{
Comparison of Analgesic Effects of UST with NSAIDs and without NSAIDs in Patients with De Quervain's Disease
}

\author{
A.B.M Zafar Sadeque ${ }^{1 *}$, Mohammad Ilias $^{2}$, Fahad Islam ${ }^{3}$, Md. Imam Shahriar ${ }^{4}$, Md. Mahfuzur Rahman ${ }^{5}$
}

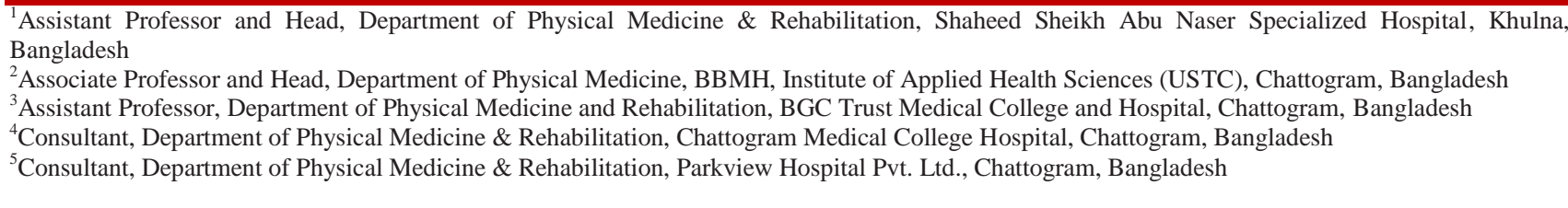

DOI: $10.36347 /$ sjams.2020.v08i09.033

| Received: 03.09.2020 | Accepted: 10.09.2020 | Published: 25.09.2020

*Corresponding author: A.B.M Zafar Sadeque

Abstract

Original Research Article

Background: De Quervain's disease has been described as an entrapment of the extensor pollicis brevis and abductor pollicis longus tendons in the first dorsal compartment of the wrist is a common cause of wrist and hand pain Treatment of the disease consists of pharmacological \& non-pharmacological. The non-pharmacological includes immobilization, therapeutic heat and cold, electrical nerve stimulator, thumb stabilizer splint, postural correction at work and the adjustment of tools and equipment. This randomized clinical trial was performed to find out the effects of UST with NSAIDs and without NSAIDs in the patients of De Quervain's disease. Methods: This randomized clinical trial was performed in the Department of Physical Medicine and Rehabilitation, Bangabandhu Sheikh Mujib Medical University, Dhaka, Bangladesh, over a period of six months. Group A-experimental or interventional group and group B-control group by randomization with the help of lottery. Experimental group was managed by activities of daily living (ADLs) instructions, ultrasound therapy (UST) with non-steroidal anti-inflammatory agents (NSAIDs gel), along with thumb spica splint. Control group B received previous management except nonsteroidal anti-inflammatory agents (NSAIDs gel). All patients received therapeutic ultrasound in a same dosage (1 watt $/ \mathrm{cm}^{2} / \mathrm{min}$ ) for 8 minutes. An evaluation was made at initial visit and two weeks interval for 6 weeks. So, there were three follow up visits and these evaluations were performed by the same investigator. In each visit, measurement of pain intensity and disability level were performed by using visual analogue scale (VAS), Tenderness Index and Patient rated wrist evaluation (PRWE) respectively. All results were recorded systematically. A post intervention result was compared with baseline result by SPSS-20. Results: Out of 60 total patients 60(100\%) had Finkelstein test positive. Significant difference between Group A and Group B was found at week 4 and Week 6 follow up $(\mathrm{P}<0.05)$ whereas other early follow up was non-significant in VAS analysis $(\mathrm{p}>0.05)$. Significant difference between Group A and Group B was found at week 4 and week 6 follow up $(\mathrm{P}<0.05)$ regarding change of tenderness and PRWE. Conclusion: Regarding treatment of De Quervain's disease, present study shown that UST with NSAIDs gel reduces the morbidity and relief of pain of patients when in comparison to other conventional treatment.

Keywords: De Quervain's disease, ultra sound therapy, thumb splint.

Copyright @ 2020: This is an open-access article distributed under the terms of the Creative Commons Attribution license which permits unrestricted use, distribution, and reproduction in any medium for non-commercial use (NonCommercial, or CC-BY-NC) provided the original author and source are credited.

\section{INTRODUCTION}

Tenosynovitis is inflammation of a tendon and its enveloping synovial sheath [1]. Stenosing tenosynovitis or de Quervain's disease is classically defined as a stenosing tenosynovitis of the synovial sheath of tendons of the abductor pollicis longus and extensor pollicis brevis muscles in the first compartment of the wrist due to repetitive use [2]. These musculotendinous units control the position and orientation, force application and joint stability of the thumb. The impaired gliding is believed to be as a result of thickening of the extensor retinaculum at the first dorsal (extensor) compartment of the wrist, with subsequent narrowing at the fibro-osseous canal [3]. Extensor triggering, which is manifested by locking in extension, is rare but has also been reported in de Quervain's tenosynovitis with a prevalence of 1.3\% [4]. Overexertion related to household chores and recreational activities including piano playing, sewing, knitting, typing, bowling, golfing, and fly-fishing have been reported to cause de Quervain's tenosynovitis. Workers involved with fast repetitive manipulations 
such as pinching, grasping, pulling, and pushing are also at risk [5]. Excessive use of the text messaging feature on a cellular phone has now also been linked to this painful condition [6]. Presenting symptoms are pain and swelling at the base of the thumb having positive Finkelstein test [7].

Patients having diabetes, RA and pregnant women are more prone to develop de Quervain's disease $[8,9]$. There is no predilection for right versus left side, and no racial differences have been observed [10]. The goal of treatment for de Quervain's disease is to relieve the pain and swelling and restore normal function. Activity modification is often the most important consideration in conservative management [11].

\section{Materials ANd Methods}

After clearance from the institutional review board of BSMMU, patient with wrist pain attending the out-patient department of Physical Medicine \& Rehabilitation BSMMU, 60 Patients with de Quervain's disease were selected from the 8th December 2015 to 7th June 2016. Patients of de Quervain's disease were allocated into two groups group A or group B by lottery. All data was recorded systematically in a semistructured questionnaire. Group A UST with NSAIDs gel (Phonophoresis) + ADLs + Thumb spica splint. Group B UST without NSAIDs gel + ADLs + Thumb spica splint. Equipment to be used for outcome is Data collection sheet, VAS, Tenderness Index, PRWE questionnaire. A thorough history was taken from the registered patients and clinical examination of the patients was done which includes general examination, musculoskeletal and neurological examination of upper limbs, examination of cervical region and wrist joint to find out the cause of wrist pain. Past history of illness and any systemic diseases was inquired cautiously. Patient who met exclusion criteria were excluded. All symptoms and signs of each participant were recorded accordingly and clinical diagnosis was made. Relevant investigation was done. Thus diagnosis of de Quervain's disease was confirmed clinically after exclusion of other possible diagnosis by related investigation. Pre intervention and post intervention pain score \& tenderness were evaluated by visual analogue scale (VAS) and Tenderness index (TI) respectively. Similarly functional status was assessed by using Patient rated wrist evaluation (PRWE) questionnaire. At first PRWE questionnaire was translated into Bangla to make it easily understand to participants. The questionnaire was finalized following pretesting. The post intervention responses were recorded at 2 weekly intervals for six weeks following initiation of treatment. All data were recorded systematically in the data sheet.

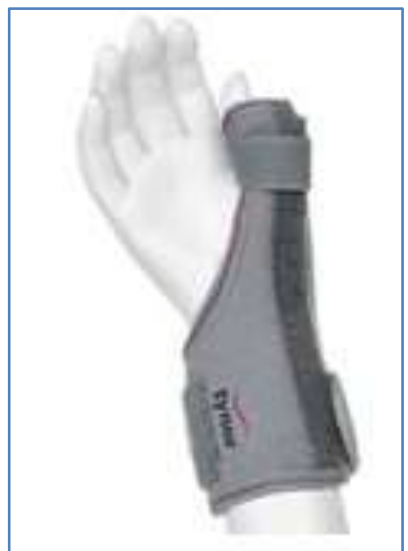

Fig-1: Thumb spica splint

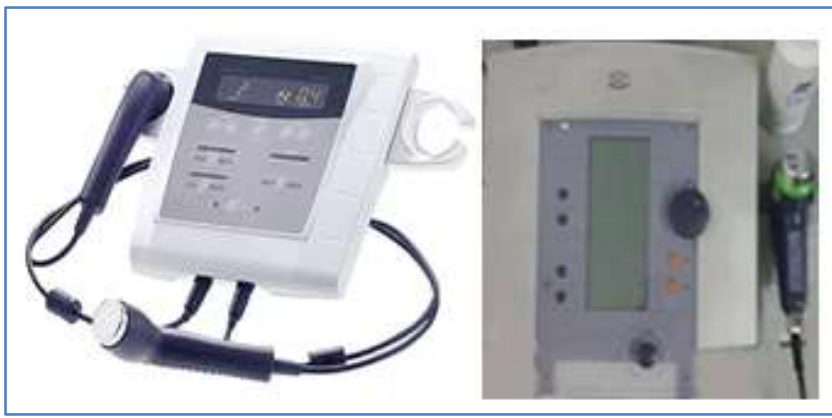

Fig-2: Ultrasound therapy machine
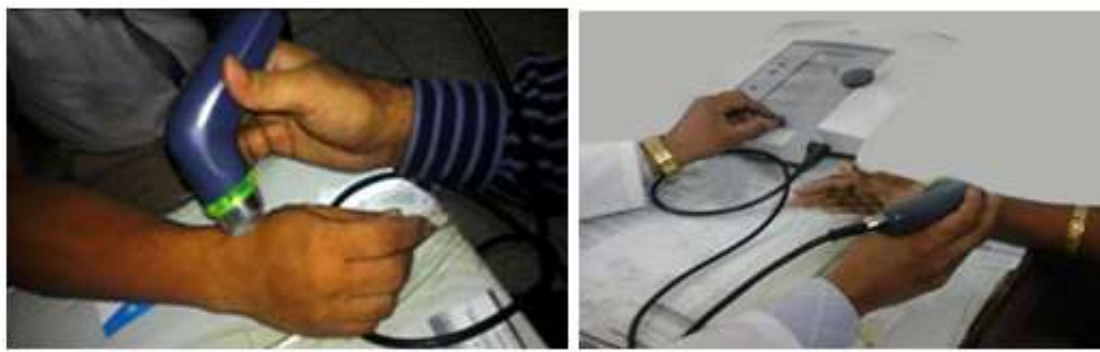

Fig-3: Patient receiving UST without NSAID and UST with NSAID gel 


\section{RESULT}

60 patients were selected for this study. They were randomly divided into 2 groups.

Table-1: Gender distribution of study patients

\begin{tabular}{|c|c|c|c|}
\hline \multirow{2}{*}{ Gender } & \multicolumn{2}{|c|}{ Group } & Total \\
\cline { 2 - 4 } & $\begin{array}{c}\text { Group A } \\
(\mathrm{n}=30)\end{array}$ & $\begin{array}{c}\text { Group B } \\
(\mathrm{n}=30)\end{array}$ & $(\mathrm{n}=60)$ No. (\%) \\
\hline Male & 6 & 10 & $16(26.6 \%)$ \\
\hline Female & 24 & 20 & $44(73.3 \%)$ \\
\hline Total & 30 & 30 & $60(100 \%)$ \\
\hline
\end{tabular}

There were 44 female (73.3\%) and 16 male (26.6\%) in the study and female male ratio was 2.75:1.

Table-2: Age distribution of the patients

\begin{tabular}{|c|c|c|c|}
\hline \multirow{2}{*}{ Age of Respondent } & \multicolumn{2}{|c|}{ Group } & Total \\
\cline { 2 - 4 } & $(\mathrm{n}=30)$ & $(\mathrm{n}=30)$ & $(\mathrm{n}=60)$ No. $(\%)$ \\
\hline 26-35 Yrs & 14 & 18 & $32(53.3 \%)$ \\
\hline 36-45 Yrs & 12 & 9 & $21(35.0 \%)$ \\
\hline $46-55$ Yrs & 4 & 3 & $7(11.7 \%)$ \\
\hline Total & 30 & 30 & $60(100 \%)$ \\
\hline
\end{tabular}

32 patients (53.3\%) were between $26-35$ years and $21(35 \%)$ patients were in $36-45$ years and $7(11.7)$ were in $46-55$ years. the mean age was 34.02 years.
Most of the patients were between ages 26-35 years in the two study groups. (Table-2)

Table-3: Occupation of the patients

\begin{tabular}{|c|c|c|c|}
\hline \multirow{2}{*}{ Occupation } & \multicolumn{2}{|c|}{ Group } & Total \\
\cline { 2 - 4 } & $(\mathrm{n}=30)$ & $(\mathrm{n}=30)$ & $(\mathrm{n}=60)$ No. $(\%)$ \\
\hline House wife & 23 & 19 & $42(70 \%)$ \\
\hline Service holder & 5 & 10 & $15(25 \%)$ \\
\hline Students & 2 & 1 & $3(5 \%)$. \\
\hline Total & 30 & 30 & $60(100 \%)$ \\
\hline
\end{tabular}

Most patient's occupation were housewife 42 $(70 \%)$. Others were service holder (Banker, Nurse, computer operator, tea maker, teacher) $15(25 \%)$ and students $2(5 \%)$.

Table-4: Socioeconomic Status of the patients

\begin{tabular}{|l|c|c|c|}
\hline \multirow{2}{*}{ Socioeconomic Status } & \multicolumn{2}{|c|}{ Group } & Total \\
\cline { 2 - 4 } & $\begin{array}{c}\text { Group A } \\
(\mathrm{n}=30)\end{array}$ & $\begin{array}{c}\text { Group B } \\
(\mathrm{n}=30)\end{array}$ & $(\mathrm{n}=60)$ No. (\%) \\
\hline Poor & 1 & 1 & $2(3.33 \%)$ \\
\hline Middle class & 28 & 28 & $\underline{56(93.33 \%)}$ \\
\hline Rich & 1 & 1 & $2(3.33 \%)$ \\
\hline Total & 30 & 30 & $\underline{60(100 \%)}$ \\
\hline
\end{tabular}

Most of the patients were middle class 56 (93.33\%).

Table-5: Involved Wrist

\begin{tabular}{|l|c|c|c|}
\hline \multirow{2}{*}{ Involved Wrist } & \multicolumn{2}{|c|}{ Group } & Total \\
\cline { 2 - 4 } & $\begin{array}{c}\text { Group A } \\
(\mathrm{n}=30)\end{array}$ & $\begin{array}{c}\text { Group B } \\
(\mathrm{n}=30)\end{array}$ & $(\mathrm{n}=60)$ No. (\%) \\
\hline Right & 26 & 28 & $54(90 \%)$ \\
\hline Left & 2 & 1 & $3(5 \%)$ \\
\hline Both & 2 & 1 & $3(5 \%)$ \\
\hline Total & 30 & 30 & $60(100 \%)$ \\
\hline
\end{tabular}

Involvement of wrists was more in the right 54 (90\%), in Group-A $26(86.6 \%)$ and in Group-B 28
(93.3\%). Whereas left wrist and both wrist involvement were less, only $3(5 \%)$ 
Table-6: Aggravating Factors

\begin{tabular}{|l|c|c|c|}
\hline \multirow{2}{*}{ Aggravating Factors } & \multicolumn{2}{|c|}{ Group } & Total \\
\cline { 2 - 4 } & $\begin{array}{c}\text { Group A } \\
(\mathrm{n}=30)\end{array}$ & $\begin{array}{c}\text { Group B } \\
(\mathrm{n}=30)\end{array}$ & $(\mathrm{n}=60)$ No. (\%) \\
\hline Wringing of cloth & 7 & 5 & $12(20 \%)$ \\
\hline Lifting of heavy objects & 5 & 5 & $10(16.66 \%)$ \\
\hline Repetitive grasping & 18 & 17 & $35(58.33 \%)$ \\
\hline Diabetes Mellitus & 0 & 1 & $1(1.66 \%)$ \\
\hline Pregnancy & 0 & 2 & $2(3.33 \%)$ \\
\hline Total & 30 & 30 & $60(100 \%)$ \\
\hline
\end{tabular}

De Quervain's disease was more found in female who had a precipitating factor as repetitive grasping $35(58.33 \%)$, some developed this condition due to lifting heavy objects such as baby 10 (16.66\%) and wringing of cloth $10(16.66 \%)$. Diabetes mellitus 1 $(1.66 \%)$ and pregnancy $2(3.33 \%)$ also precipitated the condition.
Analysis of VAS at different follow up data in both group: Significant difference between Group A and Group B was found at week 4 and Week 6 follow up $(\mathrm{P}<0.05)$.

Table-7: Pain analysis by VAS

\begin{tabular}{|c|c|c|c|c|c|c|}
\hline \multirow[t]{5}{*}{ During enrollment } & \multirow{3}{*}{$\begin{array}{c}\text { Pain on VAS } \\
\text { Mild pain }\end{array}$} & \multicolumn{2}{|c|}{ Group } & \multirow{2}{*}{\multicolumn{2}{|c|}{$\begin{array}{c}\text { Total } \\
(\mathrm{n}=60) \text { No. }(\%)\end{array}$}} & \multirow[t]{3}{*}{ P Value } \\
\hline & & \multirow{2}{*}{$\begin{array}{c}\begin{array}{c}\text { Group A } \\
(\mathbf{n}=\mathbf{3 0})\end{array} \\
1\end{array}$} & \multirow{2}{*}{$\begin{array}{c}\begin{array}{c}\text { Group B } \\
(\mathbf{n}=\mathbf{3 0})\end{array} \\
3 \\
\end{array}$} & & & \\
\hline & & & & $4(6.6 \%)$ & $60(100 \%)$ & \\
\hline & Moderate pain & 26 & 25 & $51(85 \%)$ & & \\
\hline & Severe pain & 3 & 2 & $5(8.3 \%)$ & & \\
\hline \multirow[t]{2}{*}{ After week 2} & Mild pain & 1 & 2 & $3(5 \%)$ & $60(100 \%)$ & .500 \\
\hline & Moderate pain & 29 & 28 & $57(95 \%)$ & & \\
\hline \multirow[t]{2}{*}{ After week 4} & Mild pain & 26 & 6 & $32(53.3 \%)$ & $60(100 \%)$ & .000 \\
\hline & Moderate pain & 4 & 24 & $28(46.6 \%)$ & & \\
\hline \multirow[t]{2}{*}{ After week 6} & Mild pain & 25 & 7 & $32(53.3 \%)$ & $60(100 \%)$ & .000 \\
\hline & Moderate pain & 5 & 23 & $28(46.6 \%)$ & & \\
\hline
\end{tabular}

After Week 6, mild pain in group-A 5(16.6\%) and group-B 23(76.6\%) and No pain Group-A $25(83.3 \%)$ and Group-B 7(23.3\%). Between the two study groups showed significant variation (Table 7). Post- treatment pain score showed significant improvement $(\mathrm{P}<0.01)$ in Group-A patients compared to group-

B. After week 6, Gr-1 tenderness in group-A $30(100 \%)$ and group-B $30(100 \%)$. Between the two study groups showed significant variation (Table-8). Post-treatment tenderness index showed significant improvement $(\mathrm{P}<0.01)$ in Group-A patients compared to group-B.

Analysis of patient rated wrist evaluation (PRWE) at different follow up data in both group: Significant difference between Group A and Group B was found at week 4 and week 6 of follow up $(\mathrm{P}>0.05)$ regarding PRWE.

Table-8: PRWE evaluation

\begin{tabular}{|c|c|c|c|c|c|}
\hline \multirow{5}{*}{$\begin{array}{c}\text { During } \\
\text { enrollment }\end{array}$} & \multirow{2}{*}{$\begin{array}{l}\text { Pain on } \\
\text { VAS }\end{array}$} & \multicolumn{2}{|c|}{ Group } & \multirow{2}{*}{$\frac{\text { Total }}{(\mathrm{n}=60) \text { No. }(\%)}$} & \multirow[t]{2}{*}{ P Value } \\
\hline & & $\begin{array}{c}\text { Group A } \\
(\mathrm{n}=30)\end{array}$ & $\begin{array}{c}\text { Group B } \\
(\mathrm{n}=30)\end{array}$ & & \\
\hline & Mild pain & 5 & 7 & $12(19.9 \%)$ & \\
\hline & $\begin{array}{c}\text { Moderate } \\
\text { pain }\end{array}$ & 25 & 23 & $48(79.6 \%)$ & \\
\hline & Total & 30 & 30 & $60(100 \%)$ & \\
\hline \multirow[t]{3}{*}{ After week 2} & Mild pain & 5 & 7 & $12(19.9 \%)$ & .374 \\
\hline & $\begin{array}{l}\text { Moderate } \\
\text { pain }\end{array}$ & 25 & 23 & $48(79.68 \%)$ & \\
\hline & Total & 30 & 30 & $60(100 \%)$ & \\
\hline \multirow[t]{3}{*}{ After week 4} & Mild pain & 30 & 30 & $60(100 \%)$ & . 000 \\
\hline & Total & 30 & 30 & & \\
\hline & Pain free & 23 & 5 & $28(46.4 \%)$ & \\
\hline \multirow[t]{2}{*}{ After week 6} & Mild pain & 7 & 25 & $32(53.12 \%)$ & .000 \\
\hline & Total & 30 & 30 & $60(100 \%)$ & \\
\hline
\end{tabular}


During enrollment in both groups most patients had moderate pain in group-A 25(83.3\%) and group-B 23(76.6\%). After week 4, mild pain in group-A $30(100 \%)$ and group-B 30(100\%). After week 6, Pain free in group-23(76.6\%) and group-B 5(16.6\%)
Between the two study groups showed significant variation (Table-9). Post-treatment tenderness index showed significant improvement $(\mathrm{P}<0.01)$ in group-A Patients compared to group B.

Table-9: Final outcome of treatment in the study patients

\begin{tabular}{|l|c|c|c|c|}
\hline \multicolumn{1}{|c|}{ Outcome } & Group A $(\mathbf{n}=30)$ & Group B $(\mathbf{n = 3 0})$ & Total & P value \\
\hline Completely cured & 23 & 5 & $46.6 \%$ & .000 \\
\hline $\begin{array}{l}\text { Moderate/Mild reduction of } \\
\text { symptoms }\end{array}$ & 7 & 25 & $53.33 \%$ & \\
\hline Total & 30 & 30 & $60(100 \%)$ & \\
\hline
\end{tabular}

\section{DiscuSSION}

In the present study gender in both groups male and female were matched and female to male ratio was 2.75:1. Female $44(73.3 \%)$ were more affected than male $16(26.6 \%)$. Socioeconomic status was found different in both groups where poor was 2 (3.3\%), middle class was $56(93.33 \%)$ and rich was $2(3.3 \%)$. In the present study regarding wrist involvement right wrist were involved more in Group B 28(93.3\%) than Group A 26(86.6\%). There were some patients who had both wrist involvements (5\%). All patients in both groups had some aggravating factor but relieving factors were less. It has been reported that $8.3 \%$ of patients present with upper extremity conditions as their chief complaint in chiropractic practices [12, 13]. De Quervain's has also been shown to usually present in the fifth and sixth decades of life, as well as being more common in pregnant and lactating women. The medication included non- steroidal Anti-inflammatory Drugs (NSAIDs) and analgesic, an injection of a steroid mixed with xylocaine into tendon sheaths. Decompression of the first dorsal compartment demonstrated a good result, but surgery is rarely made except if the patient does not respond well to those treatments [14]. The positive outcome was a complete resolution of the patient's complaint. Significant difference between Group A and Group B was found at week 4 and Week 6 follow up $(\mathrm{P}<0.05)$ where as other early follow was non-significant in VAS analysis $(p>0.05)$. Significant difference between Group A and Group B was found at week 4 and week 6 follow up $(\mathrm{P}<0.05)$ regarding change of tender index in Group A than Group B. Significant difference between Group A and Group B was found at week 4 and week 6 of follow up $(\mathrm{P}>0.05)$ regarding PRWE. So it can be said that group-A patients who were treated along with UST+NSAIDs had better outcome in reduction of pain and day to day activity.

\section{Conclusion}

From our study we can conclude that patient having symptoms of De Quervain's disease, getting treatment as early as possible with UST with NSAIDs is more effective than UST without NSAIDs.

\section{RECOMMENDATION}

UST with NSAIDs among the patients with de Quervain's tenosynovitis along with other conservative management is beneficial.

\section{REFERENCES}

1. http:// medical-dictionary. The free dictionary. com / tenosynovitis

2. Leslie WD. The scintigraphic appearance of de Quervain tenosynovitis. Clin Nucl Med. 2006; 31: 602-4.

3. Finkelstein H. Stenosing tendovaginitis at the radial styloid process. J Bone Joint Surg [Am]. 1930; 12: 509-540.

4. Lamphier TA, Crooker C, Crooker JL. De Quervain's disease. Ind Med Surg. 1965; 34:847856. Bibliographic Links

5. Kay NR. De Quervain's disease. Changing pathology or changing perception? J Hand Surg Br. 2000 Feb; 25(1): 65-9.

6. Ilyas AM, Ast M, Schaffer AA, Thoder J. De Quervain tenosynovitis of the wrist. J Am Acad Orthop Surg. 2007 Dec; 15(12): 757-64. Review. Erratum in: J Am Acad Orthop Surg. 2008 Feb; 16(2): 35A.

7. Khan KM, Cook JL, Bonar F, Harcourt P, Astrom M. Histopathology of common tendinopathies. Update and implications for clinical management. Sports Med. 1999; 27:393-408.

8. Walker MJ. Manual physical therapy examination and intervention of a patient with radial wrist pain: a case report. J Orthop Sports Phys Ther. 1994; 34: 761-9.

9. Khan KM, Cook JL, Bonar F, Harcourt P, Astrom M. Histopathology of common tendinopathies. Update and implications for clinical management. Sports Med. 1999; 27:393-408.

10. Ashurst JV, Turco DA, Lieb BE. Tenosynovitis caused by texting: an emerging disease. J Am Osteopath Assoc 2010; 110: 294-6.

11. Bengtson KA, Brault JS, Gerber LH. Hand disorders. In: Frontera WR, Delisa JA, Gans BM, Walsh NE, Robinson LR. Delisa's Physical Medicine \& Rehabilitation Principles and Practice. 5th ed. USA: Lippincott Williams \& Wilkins. 2010: $941-42$ 
12. Veluthamaningal CP, Winters JC, Groenier $\mathrm{KH}$, deJong BM. Randomised controlled trial of local corticosteroid injections for de Quervain's tenosynovitis in general practices.

$\mathrm{BMC}$ Musculoskelet disord. 2009; 10:131

13. Jongprasitkul H, Suputtitada A, Kitisomprayoonkul W, Pintawiruj K. Elastic bandage vs. neoprene thumb stabilizer splint in acute De Quervain's tenosynovitis. Asian Biomedicine. 2011 Apr 1;5(2):263-7.

14. Richards RR, Bigliani LU, Friedman RJ, Gartsman GM, Lannotti JP, Zuckerman JD. A Standardized method for the assessment of shoulder function. J shoulder elbow surg. 1994; 3: 347-5. 